\title{
A Feeding Tube Can Be Used for Palliative Decompression Too
}

\author{
Ah San Pang, FRCSEd
}

Dear Editor:

Palliative medicine has gently and firmly established itself in my country, Singapore. "A Cup of Hot Chocolate" published in the June 2010 issue of the Journal of Palliative Medicine is evidence of how far it has come. ${ }^{1}$ When the article appeared, the community with which author Sean Lim was affiliated announced the event widely. I celebrated it too because palliative medicine has an important role to play. I do not work in this specialty; my perspective is necessarily that of an outsider and may not be applicable outside of Singapore.

While much has been achieved, much more needs to be done. By way of example, I have used the reported case. It must be emphasized that I am not criticizing the institutions involved; sometimes it is simply just patient's choice.

A nasogastric tube, or its variation, is not comfortable at all. Thus, $23 \%$ of physical restraints used in the nursing homes in Singapore are for the sole purpose of preventing the tube from being pulled out. ${ }^{2}$ In my opinion, it is ironic when an uncomfortable option is used for palliation.

The percutaneous endoscopic gastrostomy is a better option. Although it is easily inserted using local anesthesia and sedation, tube dislodgement and difficult tube exchange can cause serious complications like buried bumper syndrome, hemorrhage, and peritonitis. Hence, it is understandable why some colleagues do not like it and advise their patients to stick with the low-risk but low-comfort nasoenteral option.

With the availability of a new gastrostomy tube that is devoid of complications associated with tube dislodgement and tube exchange, it may be time for a re-think. ${ }^{3}$ In this way, more patients may be spared the discomfort and indignity during the last phase of their journey.

\section{References}

1. Lim RCS: A cup of hot chocolate. J Palliat Med 2010;13:775.

2. Mamun K, Lim J: Use of physical restraints in nursing homes: Current practice in Singapore. Ann Acad Med Singapore 2005;34:158-162.

3. Pang AS: A new feeding tube which is secure and easy to change. Singapore Med J 2009;50:740-741.

Address correspondence to: Ah San Pang, FRCSEd

Department of General Surgery Mount Alvernia Hospital

820 Thomson Road

Singapore 574623

E-mail: pangahsan@gmail.com

Department of General Surgery, Mount Alvernia Hospital, Singapore. 